\title{
AUTOGESTIÓN Y ABANDONO INSTITUCIONAL EN EL ÁMBITO DEL FÚTBOL BARRIAL. EL CASO DE ARCO IRIS Y PUERTO MORENO, DOS CLUBES DE LA CIUDAD DE BARILOCHE, PATAGONIA ARGENTINA (1975-2018)
}

\author{
Luciano Arancibia Agüero \\ Universidad Nacional del Comahue, Argentina \\ luciano_arancibia@yahoo.com.ar
}

RESUMEN: En este artículo analizamos, en clave comparativa y relacional, la historia de los clubes Puerto Moreno y Arco Iris ubicados en la zona oeste de Bariloche (Argentina). Ambas entidades brindan espacios de contención social a través de la práctica del fútbol a cientos de niños y jóvenes provenientes de diversos barrios de la ciudad. Indagamos los factores que han facilitado o limitado sus actividades para comprender desde estos casos la lógica local de inclusión/exclusión social en relación con el deporte y el rol ejercido por el Estado. Nuestra hipótesis será afirmar que el desarrollo institucional de los clubes ha sido producto de la iniciativa de los vecinos más que de cualquier tipo de intervención estatal. Planteamos continuidades respecto a la inacción del Estado en su contribución al crecimiento de dichas instituciones y aseguramos que la autogestión de los clubes está ligada a las dificultades para asegurar la provisión de servicios a los barrios periféricos de la ciudad. Para ello, a través de un abordaje microhistórico, nos adentramos en los diversos contextos locales y nacionales desde los años setenta hasta el 2018.

Palabras clave: fútbol barrial, clubes, inclusión social, autogestión, Estado. 


\title{
SELF-MANAGEMENT AND INSTITUTIONAL ABANDONMENT IN NEIGHBORHOOD SOCCER. THE CASE OF ARCO IRIS AND PUERTO MORENO, TWO CLUBS IN THE CITY OF BARILOCHE, PATAGONIA ARGENTINA (1975-2018)
}

\begin{abstract}
On this article, we analize in a comparative and relational way the history of clubs Puerto Moreno and Arco Iris, both from the west of Bariloche (Argentina). These entities give places for social containment through the practice of soccer to children and young people from different neighborhoods of the city. We investigate the factors that have facilitated or limited their activities to understand from these cases the local logic of social inclusion/exclusion in relation to sport and the role exercised by the State. Our hypothesis will affirm that the institutional development of the clubs had been a product of the neighbors' initiative rather than of any type of state intervention. We present continuities about the inactivity of the government on its contribution to the growth of these institutions and we insure that the self-management of the clubs is related to the difficulties on provide services to the peripheral neighborhoods of the city. For this, through a microhistorical approach, we put inside the different local and national contexts from the 70s to 2018.
\end{abstract}

Keywords: neighborhood soccer, clubs, social inclusion, self-management, State.

Recibido: 6 de noviembre de 2018

Aceptado: 25 de diciembre de 2018

\section{Introducción}

El fútbol es el deporte más popular de la Argentina y es el que nuclea mayor cantidad de gente en la ciudad de San Carlos de Bariloche, una de las más importantes de la región patagónica, ubicada al oeste de la provincia de Río Negro a orillas del lago Nahuel Huapi sobre la cordillera de los Andes. En esta ciudad numerosos equipos participan en ligas de clubes federados (es decir, vinculados a la Asociación de Fútbol Argentino) y no federados (agrupados en competencias organizadas por la Municipalidad, las juntas vecinales u otras entidades civiles). En este artículo vamos a centrarnos en el estudio de caso de dos instituciones que forman parte de los campeonatos que organiza la Liga de Fútbol Bariloche (LIFUBA): la Asociación Civil, Cultural y Deportiva Puerto Moreno y la Asociación Social, Cultural y Deportiva Arco Iris, ambas pertenecientes a la zona oeste de la ciudad, que es conocida como "los Kilómetros" ${ }^{1}$.

1. La población de la zona oeste de Bariloche se asienta a lo largo de los kilómetros de extensión de la Avenida Exequiel Bustillo y de la Avenida de Los Pioneros. La numeración de las direcciones en ambos caminos indica aproximadamente la distancia respecto al centro de la ciudad. 
La primera de estas instituciones (en adelante "Puerto Moreno") se ubica en la costa del lago Nahuel Huapi a la altura del kilómetro Nº10 de la Avenida E. Bustillo, más precisamente en el barrio Pájaro Azul-Puerto Moreno, uno de los más antiguos de la ciudad ${ }^{2}$ y con un crecimiento demográfico que históricamente ha sido más lento que el de otros de la zona. Allí viven familias que pertenecen principalmente a un sector socio-económico medio y hay residencias empleadas para el turismo. La segunda (en adelante "Arco Iris") se emplaza en el corazón del barrio Virgen Misionera, situado en el kilómetro N7 de la Avenida de los Pioneros, al pie de la ladera del cerro Otto. Se trata de un barrio compuesto por sectores populares que tuvo sus orígenes en la década de 1940 pero con un gran crecimiento a partir de los años ochenta, momento en que se dio su consolidación organizativa comunitaria.

En la zona de influencia de ambos clubes se encuentran numerosos barrios del sector oeste de la ciudad que presentan diversas condiciones socio-económicas. Puerto Moreno y Arco Iris brindan espacios de formación y contención, a través de la práctica del fútbol, para cientos de niños y jóvenes de diversas edades en sus diferentes categorías infanto-juveniles. A estas se suman las categorías mayores (primera, cuarta y quinta) que participan en los torneos de LIFUBA. Las dos instituciones, con sus particularidades, tuvieron un gran crecimiento a partir de los trabajos de contención realizados con jóvenes provenientes de las zonas lindantes y del resto de la ciudad.

En este artículo realizamos un abordaje por la historia de los clubes Puerto Moreno y Arco Iris, considerando la labor formativa efectuada a través de la práctica del fútbol. Presentamos nuestra problemática a través del siguiente interrogante: ¿cuáles fueron los factores facilitadores y obstaculizadores de la implementación de la función como integrador social del fútbol y el fútbol infantil en ambos clubes desde sus orígenes hasta la actualidad? Para responder vamos a tratar los diversos contextos locales y nacionales, considerar el rol del Estado y los procesos de fragmentación socio-espacial en Bariloche a partir de su gran crecimiento desde los años setenta. Nuestro objetivo será explicar dichos factores para comprender la lógica de inclusión/exclusión social en la ciudad en relación con el deporte.

La hipótesis de nuestra investigación será afirmar que el desarrollo institucional de los clubes del oeste de Bariloche ha sido producto casi exclusivamente de la iniciativa de los vecinos más que de cualquier tipo de intervención estatal. Planteamos continuidades en el tiempo respecto a la inacción del Estado, tanto municipal como nacional, en su contribución al crecimiento de dichas instituciones y sus actividades.

2. El poblamiento de Bariloche -con las características que se mantienen aún hoy-comenzó en las últimas décadas del siglo XIX y se profundizó en las primeras del siglo XX. En Puerto Moreno residió el primer grupo poblacional constituido tras la violenta anexión del territorio por parte del Estado nacional argentino, tras la llamada "Campaña del Desierto" (1878-1885). 
Aseguramos que la autogestión de los clubes está, en parte, muy ligada a las propias dificultades estatales para asegurar la provisión de servicios a los barrios más alejados del centro de la ciudad. Las características señaladas pueden hacerse extensivas al conjunto de la actividad futbolística en Bariloche, considerando que las políticas económicas y de planificación urbana en las últimas décadas agravaron la exclusión social e implicaron la desaparición de numerosos espacios públicos utilizados para esa práctica deportiva. Sumado a esto, la fragmentación social en Bariloche, resultado de su crecimiento desorganizado, ha sido un limitante importante para la consolidación institucional de los clubes en la ciudad, los cuales se encuentran atomizados en los barrios. Pero, a su vez, también pretendemos demostrar cómo el fútbol puede ser un medio para favorecer la integración social en contextos de marginalidad, pobreza y otras problemáticas; incluso sin contar con apoyos sistemáticos por parte del Estado.

\section{Consideraciones teórico-metodológicas}

Tomando aportes de la microhistoria y la historia regional, partimos del análisis "micro" de un par de clubes y sus barrios para dar visibilidad a las particularidades de la historia del fútbol infanto-juvenil y de la sociedad de Bariloche teniendo en cuenta el acelerado crecimiento urbano y las relaciones socioeconómicas de la ciudad, a la vez que rescatamos la importancia del contexto nacional en que se inserta el objeto abordado. Algunos aspectos como la desaparición de canchas, la violencia en el fútbol y la falta de infraestructura, vistos a través de los clubes seleccionados, ayudarán a explicar las características más globales del desenvolvimiento del fútbol local. Además, nuestro abordaje contribuirá a conocer los desarrollos y dificultades de las organizaciones de los sectores populares bajo los diversos contextos, así como también las dinámicas de inclusión y exclusión socio-espacial en las últimas décadas.

En definitiva, la reducción de la escala de observación apunta a la lectura de un proceso más amplio. Consideramos que las prácticas deportivas no pueden separarse de las dimensiones social, política, económica y cultural del contexto en que se desarrollan. Además, hacemos hincapié en el lugar ocupado por los sectores populares de Bariloche, de manera que también ubicamos nuestro análisis en la perspectiva de la historia social "desde abajo".

La investigación se encuadra en una metodología cualitativa ya que apunta a la comprensión de las problemáticas sociales planteadas. Se trata de un estudio de caso que se centra en la exploración de las realidades particulares de los clubes. Para ello, analizamos las relaciones sociales implicadas y el contexto en que se desenvolvieron. Siendo historia reciente, empleamos entrevistas como técnica para recuperar los testimonios orales de los propios actores. A su vez, la información recolectada en las mismas fue profundizada con el análisis de fuentes escritas. Específicamente, recurrimos a biblioratos de los clubes que incluyen actas, registros contables, notas, entre otros. También abordamos docu- 
mentos de la Asociación Vecinal Pájaro Azul, la Biblioteca Francisco P. Moreno y la Escuela $\mathrm{N}^{\circ} 44$ de Puerto Moreno. Además, revisamos artículos de prensa del diario Río Negro y de los periódicos locales El Cordillerano, Adrenalina y Bariloche 2000. A esto sumamos documentaciones de distinto tipo brindadas gentilmente por dirigentes, ex dirigentes y allegados a los clubes.

\section{Consideraciones previas para comprender la dinámica de la sociedad y el fútbol barilochense}

San Carlos de Bariloche, emplazada a orillas del lago Nahuel Huapi sobre la cordillera de los Andes, es una de las ciudades más importantes de la Patagonia argentina. Se ubica al oeste de la provincia de Río Negro y constituye uno de los principales centros turísticos del país. Sus orígenes se remontan a los últimos años del siglo XIX y las primeras décadas del siglo XX como una pequeña colonia agrícola-ganadera que mantenía fuertes vínculos comerciales con el sur de Chile. La población se caracterizó por aquel entonces por poseer, justamente, una fuerte impronta chilena, sumado a la llegada de migrantes de procedencia europea. Las sucesivas oleadas migratorias contribuyeron a la configuración de una sociedad barilochense con gran diversidad cultural.

La matriz económica inicial comenzó a modificarse a lo largo de la década de 1920, cuando los gobiernos de Argentina y Chile aplicaron medidas proteccionistas que limitaron el comercio trasandino de materias primas. Luego, la crisis económica internacional de 1929-1930 propició cambios en las circunstancias del modelo agro-exportador, motivando un drástico giro para Bariloche, que pasó de ser un pueblo agrícola-pastoril a ser un destino turístico de reconocimiento internacional ${ }^{3}$. Esto se vio favorecido por la creación de la Dirección de Parques Nacionales en 1934, que representaba la presencia del Estado central en la zona y que impulsó una política de desarrollo del turismo para la región. Simultáneamente, se concretó la finalización de una línea férrea que permitió unir Buenos Aires con Bariloche. Ambas iniciativas fueron fomentadas por el deseo del gobierno nacional de "argentinizar" los territorios de frontera que mantenían débiles relaciones con las áreas centrales del país ${ }^{4}$.

La particular heterogeneidad de la población barilochense a la que hacíamos referencia antes les proporcionó características muy específicas a las prácticas deportivas en la región. Si bien los primeros clubes de fútbol de Bariloche surgieron en la segunda década del siglo XX, estos inicios se dieron de forma caótica debido a la inexistencia de alguna entidad reguladora formal

3. Méndez, L., Estado, frontera y turismo. Historia de San Carlos de Bariloche. Buenos Aires 2010, p. 230.

4. Nestares, J. A., Clase de fútbol. Sectores populares y asociativismo deportivo en Bariloche. La experiencia de la ADEFUL (1975-2015), Bariloche 2015, p. 24. 
que organizara las actividades. Al igual que en otras zonas de la Patagonia, la temprana aparición de equipos de fútbol estuvo vinculada a los objetivos de moralizar y disciplinar a algunos sectores de la sociedad. Sin embargo, más allá de este desarrollo incipiente, no fue sino a partir de los años treinta cuando la actividad futbolística tuvo un mayor impulso en Bariloche. Ello fue de la mano del crecimiento demográfico y el incremento de las conexiones con la capital del país, lo que permitió la introducción en la ciudad de los ideales de la época, elaborados por los intelectuales porteños, que otorgaban "a la actividad física y al deporte un rol formador, principalmente como motor moral de la juventud y la niñez" ${ }^{\prime \prime}$.

Durante dicha década, la práctica y el espectáculo del fútbol en Bariloche se convirtieron en una realidad consolidada. La prensa llevaba adelante una amplia cobertura del deporte en la ciudad y cientos de personas asistían a ver los partidos. De la mano de esta popularización, en 1939 surgió la primera organización formal de fútbol en Bariloche, junto a la creación de diversos clubes que comenzaron a sistematizar la práctica del deporte. De esta manera, se dio inicio a la institucionalización de la actividad que hasta ese momento se había llevado a cabo de forma irregular. Cabe destacar, según Mariano Chiappe, las actividades que conllevaba el fútbol fueron desarrolladas en Bariloche desde un principio por iniciativa de la propia población, pero no contaron con una participación activa por parte del Estado nacional.

Si bien es cierto que el Estado buscó utilizar al deporte como difusor de valores nacionalistas e instrumento para la formación de ciudadanos, lo cierto es que los intentos por influir en la práctica física no tuvieron la misma trascendencia en las regiones alejadas del centro administrativo de la Argentina. En efecto, el fútbol en Bariloche tuvo su propio desarrollo, que respondía a las particularidades de la sociedad local ${ }^{6}$. De acuerdo con dicho autor, en el momento de la fundación del fútbol en Buenos Aires, no hay correspondencia entre los principales centros urbanos y la región del Nahuel Huapi, ya que en esta última no se arraigó la idea de un estilo argentino de juego. Además, la fundación de clubes en Bariloche fue muy posterior a la expansión en Buenos Aires. Entre los años veinte y cuarenta surgieron una gran cantidad de equipos en la ciudad cordillerana, pero la popularización del deporte no fue acompañada por la profesionalización que sí se vio en la capital del país. Este desfasaje se puede explicar justamente a partir de la falta de intervención estatal en la práctica del fútbol en la región, lo que sería una constante en las décadas siguientes.

5. Chiappe, M., “iA la pelota! Fútbol, popularidad y hombría. Entre la sociedad civil y la intervención estatal. Bariloche, 1920-1945", Méndez, L. y Podlubne, A. (comps.), Tiempo de jugar, tiempo de aprender. Educación, museos y prácticas corporales en la Patagonia Norte, 1910-1955, Buenos Aires 2016, p. 181.

6. Chiappe, M., “¡A la pelota! Fútbol, popularidad y hombría...”, pp. 176-179. 
Por otra parte, a mediados del siglo XX la atención gubernamental en la ciudad se centró en fomentar otras actividades deportivas más ligadas al desarrollo del turismo, principalmente los deportes de montaña como el esquí y la escalada ${ }^{7}$. Cabe destacar, a partir de 1946, los gobiernos de Juan Domingo Perón en Argentina se caracterizaron por el nuevo papel del Estado en el deporte, reorganizando entidades, otorgando subsidios y brindando apoyos a distintas asociaciones y clubes de una forma que no tuvo precedentes en la historia del país ${ }^{8}$. Sin embargo, incluso durante el peronismo (1943-1955) siguió sin existir una relación formal entre el Estado nacional y el fútbol barilochense.

En los años sesenta, Bariloche se transformó en una ciudad con una economía dependiente casi exclusivamente de la actividad turística, abandonando por completo lo que quedaba de la vieja matriz agrícola-pastoril. En ese momento, el poblado inició un crecimiento que se dio de forma fragmentada y desorganizada, con un fuerte peso ganado por los intereses privados del sector inmobiliario por sobre la planificación urbana estatal. Por ese entonces, ya existía un equipo representativo de cada uno de los barrios, salvo excepciones. A partir de allí comenzaron a organizarse los "Campeonatos Comerciales de Fútbol", cuya denominación se basaba en el hecho de que la mayoría de los equipos representaba a los distintos comercios de la ciudad. Muchos clubes contaban con jugadores amateur provenientes de los sectores populares, incluyendo empleados, pequeños comerciantes, entre otros. Con esta base, algunos equipos lograron armar planteles que alcanzaron destacadas participaciones contra los más poderosos clubes del Valle de Río Negro ${ }^{9}$. Además, este desarroIlo futbolístico permitió la presencia de equipos barilochenses en el Torneo del Interior del Consejo Federal del Fútbol Argentino.

Por otra parte, la actividad de la Liga de Fútbol de Bariloche (principal entidad reguladora a nivel local, vinculada a la Asociación de Fútbol Argentino) comenzó a nuclearse en el Estadio Municipal, aunque muchos otros espacios públicos también fueron sitios en los que se desarrolló la práctica del deporte, tanto federado como no federado. Estos espacios, principalmente terrenos baldíos de la ciudad, además fueron sede del despegue del fútbol infantil en Bariloche, impulsado en los años sesenta principalmente por referentes de la Iglesia católica $^{10}$, entre los que se destaca el Padre Videla ${ }^{11}$. Sus torneos nucleaban los

7. Mendoza, L., El Baby Fútbol ¿Productor o reproductor de masculinidades? El fútbol infantil en San Carlos de Bariloche en la primera mitad del siglo XX. Bariloche s/f., p. 4. $10-11$

8. Rein, R., La cancha peronista. Fútbol y política (1946-1955). Buenos Aires 2015, pp.

9. Jalil, J., El deporte de mi pueblo. Bariloche 2003, pp. 15-17.

10. Nestares, J. A., Clase de fútbol. Sectores populares y asociativismo deportivo en Bariloche..., pp. 53-57.

11. El Padre Juan Carlos Videla (1907-1989), nacido en Villa del Rosario (provincia de Córdoba), fue un cura salesiano que, a lo largo de toda su vida, estuvo encargado de la orga- 
días domingo a una gran cantidad de niños y jóvenes de toda la ciudad, pero principalmente de los barrios más carenciados que comenzaban a expandirse hacia el sur.

\section{Desarrollo: La fundación del club Puerto Moreno y su desarrollo durante la última dictadura cívico-militar argentina}

A principios de los años setenta, la zona de Puerto Moreno aumentó su poblamiento en concordancia con el acelerado crecimiento demográfico en toda la ciudad de Bariloche, la cual se consolidó como centro turístico internacional. En efecto, ante la instalación de nuevas familias, mayor cantidad de jóvenes demandaban desarrollar actividades deportivas frente a la ausencia de lugares destinados para ello en el sector. Así, el 16 de septiembre de 1975 se fundó el Club Atlético Puerto Moreno por iniciativa de vecinos del barrio que se propusieron brindar a la juventud de la zona oeste un espacio "para su sana formación física y moral".

El club ocupó el predio donde se halla emplazado actualmente mediante un permiso de uso precario otorgado en 1977 por la Comisión Nacional de Energía Atómica (CNEA), propietaria de las tierras que bordean la usina eléctrica de Puerto Moreno. En ese momento se conformó un equipo para participar en el torneo oficial de LIFUBA y se adecuó la cancha para ello. Algunos de los miembros fundadores del club que eran empleados de la Cooperativa de Electricidad Bariloche se encargaron de estas tareas de acondicionamiento del predio a la par que trabajaban en la instalación del cableado eléctrico para la zona. Luego, la CNEA autorizó la colocación del alambrado perimetral del campo de juego y la construcción de vestuarios y sanitarios, exigidos por la AFA para competir como club federado. La buena relación con la CNEA muestra la creación de redes de sociabilidad del club con otras instituciones, lo que lentamente lo fue convirtiendo en un centro de anclaje para la identidad barrial.

En sus comienzos, Puerto Moreno tuvo buenos resultados deportivos en los campeonatos oficiales de fútbol. Además, el club pudo conformar equipos juveniles de básquet, vóley y atletismo que participaron en competiciones locales. Estos logros se concretaron pese a que la institución contaba con pocos recursos materiales. Sin embargo, por esa misma limitación no pudieron efectuarse los proyectos de infraestructura planteados al momento de crearse la institución, ya que implicaban un presupuesto considerable, a la vez que se debían afrontar los altos costos de las competencias. Esto motivó a las primeras dirigencias del club

nización de numerosas Oratorias Festivas destinadas a la educación física y espiritual de los jóvenes de diversas localidades de todo el país. El gimnasio municipal de San Carlos de Bariloche, ubicado en las calles Ruiz Moreno y Elflein, lleva su nombre como homenaje al trabajo realizado con los niños y jóvenes de la ciudad. 
a buscar, desde fechas muy tempranas, apoyos económicos de otras instituciones y solicitar subsidios al gobierno nacional, para lo cual se apeló a su carácter de sociedad civil sin fines de lucro.

Según Julia Gerlero, la última dictadura cívico-militar argentina (1976-1983) intentó intervenir en las prácticas deportivas con el objetivo de imponer control sobre la población y lograr un cambio social a través de la transmisión de valores patrióticos y cristianos $^{12}$. La dirigencia de Puerto Moreno manifestaba la misma necesidad de educar y "orientar" a los jóvenes "vulnerables" de la ciudad a través del deporte, tratando de evitar que se decidan "por una vida fácil" contraria a la moral. Pese a esta "adecuación" discursiva con respecto a la función que se les atribuía a las actividades deportivas al interior de la sociedad, lo cierto es que los apoyos estatales para la institución nunca llegaron, lo que da cuenta del límite de los alcances de las políticas planteadas desde el Estado ${ }^{13}$. Esto se explica en gran medida por la falta de interés del gobierno de facto en intervenir en el desarrollo de las actividades de las asociaciones civiles y deportivas como las propuestas por el club Puerto Moreno. A esto podría sumarse la grave crisis política y económica que atravesaba la Argentina durante los últimos años de la dictadura como consecuencia de la implantación de políticas de tinte neoliberal sustentadas en el terrorismo de Estado. Dichas medidas sumergieron al país en una crisis con caída de los salarios, gran inflación y endeudamiento externo.

Cabe aclarar, en estos años se dio el surgimiento de algunos equipos de fútbol barrial en Bariloche. En cierta medida, esto puede ser atribuido al clima de euforia que generó el Mundial organizado en Argentina en 1978, que fue ganado por el país organizador. Pero, principalmente, la explicación reside en el crecimiento urbano y demográfico de la ciudad, lo que trajo consigo la conformación de nuevas identidades barriales. De esta manera, la multiplicación de los equipos de fútbol no debe ser pensada como resultado de alguna política o iniciativa por parte del Estado.

Entonces, sin apoyos, Puerto Moreno realizó distintas actividades para costear sus gastos, tales como organizar rifas y ofrecer bonos contribución. El fracaso de estas iniciativas se debió a la corta trayectoria del club, la

12. Gerlero, J. C., "La imposición del ocio. Características del Modo de Recreación de la última dictadura militar en Argentina", Revista Educación física y deporte. Medellín 2012, pp. 989-997.

13. La manipulación del deporte por parte del gobierno de facto fue muy notable especialmente en la organización de eventos de escala masiva. El ejemplo paradigmático de ello fue la organización del Mundial de Fútbol de Argentina 1978, el cual fue utilizado como un medio para reposicionar la imagen del régimen militar, tanto hacia el interior del país como a nivel de la política internacional, $y$, de esta manera, contrarrestar las graves denuncias que recaían sobre el gobierno por las violaciones contra los Derechos Humanos. Sin embargo, la intervención sobre el ámbito deportivo no se manifestó de igual forma en apoyos al desarrollo de las entidades "de base" que organizaban las actividades, tales como los clubes de barrio. 
falta de experiencia de la conducción y la desorganización interna. Los problemas económicos -incluyendo el arrastre de varios años de deudas- y los desentendimientos dirigenciales derivaron en la disolución de la Comisión Directiva y el incumplimiento de las obligaciones institucionales, motivo por el cual el gobierno de la provincia de Río Negro procedió en 1984 al retiro de la personería jurídica y el club fue desafiliado de LIFUBA.

\section{Al borde del abandono: El declive del club Puerto Moreno}

En las últimas décadas, la ciudad creció sin planificación estatal por parte de los sucesivos gobiernos y regida por la lógica del mercado de tierras, de manera que no se consideró las demandas de los sectores populares y sí se priorizó la imagen de Bariloche como ciudad "postal". Desde allí aumentaron las dificultades para brindar servicios públicos a la población y los nuevos barrios se caracterizaron por las pobres condiciones habitacionales. La predominancia del turismo como actividad económica, el crecimiento demográfico y la composición social heterogénea contribuyeron a la conformación de una ciudad con gran fragmentación socio-espacial.

En efecto, se instauró en los años ochenta en el imaginario local la representación de Bariloche como la ciudad de las "dos caras": por un lado, la cara que corresponde con la zona del casco urbano denominada como "el Centro", que mira hacia el lago Nahuel Huapi, muy vinculada al turismo y con buenas condiciones socio-económicas; $y$, por otra parte, la zona conocida como "el Alto", ubicada hacia el sur, con una población integrada en gran medida por migrantes latinoamericanos e internos que vive bajo condiciones muy desfavorables. Esta última es la parte de la ciudad que el discurso hegemónico ha intentado ocultar, omitiendo la complejidad socio-espacial que hay en Bariloche, mientras que naturaliza la precariedad al asociarla con factores raciales y espaciales ${ }^{14}$. A su vez, la dicotomía entre el Centro y el Alto deja afuera las realidades existentes al interior de la zona de "los Kilómetros", desconociendo la diversidad de situaciones sociales que presenta el oeste de la ciudad. Por lo tanto, la complejidad y heterogeneidad en Bariloche más bien permitiría hablar de una ciudad de múltiples caras ${ }^{15}$.

A partir del retorno de la democracia en 1983, el discurso gubernamental hizo hincapié en la defensa de la institucionalidad, la participación ciudadana

14. Barelli, A. I. y Azcoitía, A., "Construcciones identitarias hegemónicas y estrategias sociorreligiosas de visibilización de los migrantes latinoamericanos en San Carlos de Bariloche (1970-2000)", Revista Quinto Sol 19 (2). Santa Rosa, La Pampa 2015.

15. Matossian, B., "Dimensiones objetivas y subjetivas de la segregación urbana: el caso de San Carlos de Bariloche", XI Jornadas Argentinas de Estudios de Población. Asociación de Estudios de Población de la Argentina. Neuquén 2011. 
en el espacio público y la igualdad de oportunidades. Pero la materialización de este discurso muchas veces se vio limitada por la poca fuerza del gobierno para revertir la situación de crisis económica y social dejada por la dictadura. El incremento acelerado de los precios, que desembocó en la crisis hiperinflacionaria de 1989-1990, aumentó los niveles de pobreza de la población en todo el país. A esto se sumaron las características propias de la sociedad local con un crecimiento urbano que marginaba a los sectores populares.

Durante los años ochenta surgieron en Bariloche numerosas juntas vecinales que buscaban hacer frente a las demandas que el Estado no podía satisfacer. Según Laura Kropff, muchas de estas juntas se fortalecieron dando respuesta a algunas de las demandas económicas y políticas de los nuevos barrios ${ }^{16}$. Los vecinos de Puerto Moreno no vivían las mismas condiciones de precariedad sufridas por los pobladores del Alto de la ciudad, pero el barrio también se vio afectado por la poca eficiencia del gobierno municipal para proporcionar servicios públicos a una ciudad en expansión. Como dijimos, el oeste de Bariloche se encontraba en pleno proceso de crecimiento poblacional siguiendo la tendencia del resto de Bariloche. Fue así como se creó la Junta Vecinal Pájaro Azul en 1980 (convertida en Asociación en 1981) por iniciativa de un conjunto de vecinos que se unieron con el objetivo de mejorar la calidad de vida de la gente del barrio, impulsar obras de infraestructura y solucionar el problema específico de la falta de abastecimiento de agua potable en la zona.

Sin embargo, de acuerdo con los historiadores Paula Núñez y Ricardo Daniel Fuentes, los espacios formales que han regido a las juntas suelen dificultar la participación de los vecinos en los procesos de toma de decisión y su efectiva integración social ${ }^{17}$, especialmente por las tramas burocráticas que las atraviesan. Por eso, frente a la pobreza y el abandono institucional, las poblaciones de los barrios han desarrollado otras formas de participación que no se corresponden con los espacios institucionales formales. En este punto, el club de fútbol se convirtió en un ámbito complementario de suma importancia a través del cual se difundieron con gran éxito los valores democráticos. Allí, los sectores populares pudieron manifestar su presencia en el espacio público. La solidaridad y la igualdad de oportunidades generalmente ocuparon la base de la organización institucional y de la práctica deportiva.

En el caso de Puerto Moreno, el discurso instaurado no fue acompañado por un apoyo estatal al desarrollo de sus actividades y la estructura institucional del club quedó al borde del abandono por más de una década. Durante estos

16. Kropff, L., "Migración e identidad en San Carlos de Bariloche", V Congreso de Antropología Social. La Plata 1997.

17. Núñez, P. y Fuentes, R. D., "Formas de participación en procesos democráticos recientes. Sociedad civil en San Carlos de Bariloche", Revista de pensament i Analisi 8. Castellón de la Plana 2008. 
años, la frágil continuidad de la institución estuvo marcada por serias carencias materiales. Sin personería jurídica, las posibilidades de obtener ayudas estatales se volvieron nulas. Esto explica la necesidad de establecer alianzas con otras organizaciones para aliviar las cargas económicas. Se trató de una estrategia de supervivencia que le permitió al club mantener - de manera muy precaria- su espacio y dar continuidad a las actividades deportivas en un contexto muy difícil para la sociedad barilochense y para el fútbol local.

De esta manera, luego de su desafiliación de LIFUBA, Puerto Moreno continuó usando sus instalaciones para la realización de torneos de fútbol "libre" (independiente de la liga local vinculada a la AFA). Además, a mediados de los ochenta la institución se combinó con una agrupación hípica que comenzó a realizar domas y jineteadas en el predio. Más adelante, el club volvió a volcarse de lleno al fútbol y llevó adelante una alianza a principios de los noventa (y hasta 1996) con el ya extinto Deportivo Paraguayo, el equipo de la Colectividad Paraguaya en Bariloche, para fortalecerse y participar en los torneos. También hubo esporádicas iniciativas de formación de categorías de fútbol infantil libre.

El fútbol libre es una práctica de los sectores populares de Bariloche que tiene como base de referencia a los barrios, en torno a los cuales se afirman distintas identidades. De acuerdo con Javier Nestares, a mediados de los ochenta esta actividad atravesaba una crisis debido al aumento de la violencia y la pérdida de espacios físicos utilizados para el fútbol ${ }^{18}$. Los conflictos entre jugadores e hinchas trascendían el ámbito de las canchas, Ilegando hasta las calles e incluso a los hogares. Dicha violencia funcionaba como un medio para manifestar la inscripción territorializada en torno a los barrios, y actuaba como un mecanismo de "defensa" de los lugares de residencia.

Una causa de los hechos conflictivos fue la inacción del Estado respecto a los sectores más vulnerables de la ciudad. Esto se vio agravado por los procesos de fragmentación y segregación socio-espacial en Bariloche que dieron lugar a diversas y desiguales dinámicas barriales. Ciertamente, las políticas de Estado definieron la conformación barrial actual. Como parte de ello, las relocalizaciones forzosas de los vecinos más carenciados en áreas periféricas al sur de la ciudad $^{19}$, durante los años setenta y primera mitad de los ochenta, marcaron el puntapié inicial de la cadena de violencia que sufren los sectores de más bajos recursos de la ciudad hasta la actualidad, la cual se manifiesta también a través de diversas formas de marginación y discriminación. La violencia en el fútbol, entre diferentes equipos y, por ende, entre diferentes barrios, en gran medida

18. Nestares, J. A., Clase de fútbol. Sectores populares y asociativismo deportivo en Bariloche. La experiencia de la ADEFUL (1975-2015). Bariloche 2015.

19. Los nuevos barrios del sur de la ciudad, algunos de ellos originados a partir de planes de viviendas solidarias, se caracterizaron por las pobres condiciones habitacionales y la precariedad edilicia. 
explica que el club Puerto Moreno haya priorizado otro tipo de actividades durante algunos años.

Por otra parte, numerosos "potreros" de la ciudad de uso común fueron paulatinamente ocupados y reemplazados con construcciones producto del crecimiento urbano y no se reasignaron nuevos lugares para el deporte. La desaparición de espacios públicos fue un problema tanto para el fútbol libre como para el fútbol federado ${ }^{20}$. Este proceso, incentivado por las presiones del sector inmobiliario con aval del Estado, jugó en contra del despliegue de las potencialidades integradoras del deporte en Bariloche. Aun así, Puerto Moreno contaba con una cancha "propia" que continuaría siendo utilizada por muchos equipos y jóvenes de toda la ciudad.

\section{La lucha por la cancha en un barrio popular: El surgimiento del club Arco Iris}

El barrio Virgen Misionera también tuvo una explosión demográfica a partir de los años setenta y ochenta, favorecida por la adquisición de terrenos relativamente más económicos en comparación con otras áreas de la ciudad. Como vimos en el caso anterior, el acelerado crecimiento y densificación del barrio fue acompañado por el encarecimiento de la prestación de servicios para la población. A esto se agregó la ocupación de terrenos cuyos propietarios permanecieron ausentes durante muchos años.

De esta manera, según Tomás Guevara, Virgen Misionera se convirtió en uno de los barrios populares de la zona oeste caracterizado por padecer la misma realidad de segregación socio-espacial que sufren los vecinos del Alto al sur de la ciudad ${ }^{21}$. Sumado a esto, la crisis económica durante los años ochenta

20. Javier Nestares desarrolla la creación de la Asociación de Deportes y Fútbol Libre (ADEFUL) en Bariloche a fines de 1986 y su posterior consolidación institucional. Se trata de un caso de organización de los sectores populares en torno al asociativismo deportivo. Su nacimiento se dio como respuesta a la crisis que atravesaba el fútbol libre a principios de los años ochenta. La unión de equipos con anclaje barrial en busca de objetivos comunes permitió hacer frente a los hechos de violencia en las canchas a través de la creación de reglamentaciones acordadas por todos los integrantes de la organización. La Asociación pudo obtener su propio predio para la práctica deportiva cuando adquirió un lote en 1989 a través de gestiones realizadas con el gobierno municipal. Allí se construyó un gimnasio, inaugurado en 1996, gracias al trabajo voluntario de los asociados. La constitución de una sede común también permitió aliviar algunas de las divisiones y tensiones que existían dentro del ámbito del fútbol barrial. De esta manera, ADEFUL les permitió a sus integrantes participar en un sistema de intercambios, donde los miembros no se vieron excluidos del resto de la sociedad debido a la creación de una nueva identidad en torno a la organización. Como parte de esa identidad se destaca la decisión de los miembros de ADEFUL de dedicarse al fútbol amateur, dejando de lado el profesionalismo más ligado a las competencias de LIFUBA.

21. Guevara, T. A., "¿Y el título para cuándo? El proceso de regularización del barrio Virgen Misionera", Cadernos Metrópole 18 (35). San Pablo 2016, pp. 119-144. 
incrementó los niveles de pobreza y desocupación de sus pobladores (muchos de ellos trabajadores independientes, dedicados al rubro de la construcción y el trabajo doméstico). Además, los ocupantes de tierras, los vecinos oriundos de Chile o de las zonas rurales soportaron la estigmatización por parte de los vecinos de otros barrios. En este sentido, el discurso sostenido por una parte de la sociedad se encargó de justificar las dificultades del Estado para brindar servicios a la población a través de argumentos discriminadores que señalaron a los pobladores de origen chileno como "intrusos" e importadores de problemáticas ${ }^{22}$.

A principios de dicha década, algunos pobladores del sector se movilizaron para llevar adelante una nueva experiencia de organización y participación comunitaria destinada a paliar las situaciones de marginalidad e injusticia social que padecían los vecinos del barrio. El principal impulsor de esta iniciativa de trabajo era el sacerdote católico Juvenal Currulef, arribado al barrio en 1981, cuyo accionar se enmarcaba en el clima de ideas generado a partir del advenimiento de la democracia y la impronta de los obispos de Río Negro y Neuquén, cercanos a la corriente de la Teología de la Liberación y el principio de la "opción por los pobres".

Las principales estrategias de esta experiencia estuvieron dadas por la lucha por la tierra, la educación y la evangelización. Sus principales anclajes institucionales eran la parroquia Virgen Misionera y las diversas instituciones educativas (públicas de gestión social) que fueron surgiendo y agrupándose alrededor de la "Fundación Gente Nueva", constituida a partir del año 1989. Frente a las amenazas de erradicación de algunos pobladores promovidas por la Municipalidad y por los dueños de los lotes del barrio, el "Equipo Pastoral de Tierra" llevó adelante las gestiones que permitieron a los vecinos instalados convertirse en dueños de terrenos, lo que marcó un antes y un después en las relaciones intracomunitarias. En este marco se dio el surgimiento de la Asociación Social, Cultural y Deportiva Arco Iris.

El club Arco Iris surgió en el año 1986 y logró su personería jurídica al año siguiente, el 2 de septiembre de 1987. Los antecedentes de la institución se remontan a los encuentros organizados desde fines de los años sesenta en el

22. Las dictaduras de la segunda mitad del siglo XX fomentaron el imaginario de Bariloche establecido en los años treinta que instaló como referencia pionera de la ciudad a la minoritaria población centroeuropea, invisibilizando la impronta de la migración chilena y de otras migraciones nacionales y externas que nutrieron el crecimiento demográfico. En estos momentos la exclusión se fortaleció como resultado de las iniciativas estatales que exacerbaron la xenofobia, la precarización laboral y los cambios en la organización socio-espacial de Bariloche. De la mano de ello se llevaron adelante intentos de relocalización poblacional compulsiva, producto de presiones inmobiliarias y la aplicación de un modelo de planificación urbana que reservó las tierras periféricas a los sectores populares, por fuera de la ciudad turística. 
predio actual del club, con la participación de equipos de Virgen Misionera y de los barrios cercanos, y una gran asistencia de público. Estos encuentros, muchas veces cargados de violencia, dan cuenta de una gran rivalidad incluso al interior del barrio. Esa dinámica perduró por unos quince años hasta que, en 1982, en el marco de las presiones de erradicación a las que hacíamos referencia antes, se produjo la compra de un lote de la cancha y el inicio de la construcción de una vivienda en el lugar.

Frente a esta situación, los jugadores de los distintos equipos emprendieron en forma conjunta las gestiones para recuperar el espacio, acompañados por Currulef y sus colaboradores. Gracias a ello pudieron conservar el terreno a través de un acuerdo (un trueque) entablado con el propietario de la vivienda, y se compraron tres lotes de la cancha. Una vez cumplido este objetivo común, el sacerdote y los vecinos buscaron implementar diversas estrategias para superar dicha rivalidad, entre las que se destacó la idea de conformar un único equipo que representara a todo el barrio en los torneos organizados por la Liga de Fútbol Bariloche. De esta manera, Arco Iris nació con el propósito de fomentar la participación y organización de campeonatos junto a la realización de "otras actividades que contribuyan a mejorar el nivel de vida del barrio".

Entonces, el caso de Virgen Misionera es una muestra clara de cómo la conformación territorial en Bariloche ha estado muy determinada por el funcionamiento del mercado de tierras y las disputas por la apropiación y uso del espacio urbano $^{23}$. Ante las condiciones de pobreza, marginalidad y abandono del Estado, muchas personas vieron en el barrio su principal refugio, el cual también pasó a ser un lugar de inscripción colectiva a partir de su lugar privilegiado para la organización de solidaridades y cooperaciones. Y en este punto no debemos dejar de destacar al equipo de fútbol como ámbito importante en el cual los barrios adquieren un sentido de pertenencia para los individuos. Además, el fútbol se convierte en un campo a través del cual los sectores populares pueden alcanzar visibilidad y manifestar su participación en el espacio público. De esta manera, constatamos cómo las diversas organizaciones y clubes deportivos son ámbitos capaces de generar espacios de inclusión social y autonomía al margen del Estado, o, mejor dicho, como consecuencia de su ausencia o inacción.

\section{El "Fenómeno Arco Iris" y el renacer del "Pájaro" en el contexto del neoliberalismo y la crisis del 2001}

Al promediar la década del noventa, la ciudad se sumergió en una profunda crisis social y económica producto de la aplicación de políticas neoliberales en todo el país impulsadas por el gobierno de Carlos S. Menem. Dichas políticas

23. Núñez, P. y Guevara, T., "La ciudad en disputa: desarrollo urbano y desarrollo económico en San Carlos de Bariloche, Argentina", Revista Diálogo Andino 45. Arica 2013. 
a nivel nacional se basaban en la libre circulación de mercancías y de capitales, la reducción del gasto público, las privatizaciones, la desindustrialización y el recorte de personal en las empresas estatales. En efecto, conllevaron un aumento de la desocupación, la precarización y la flexibilización del trabajo en la mayoría de los sectores, así como también la pérdida de reivindicaciones laborales históricas. En efecto, crecieron los niveles de pobreza y exclusión de amplios sectores de la población barilochense. Tanto Virgen Misionera como Pájaro Azul no fueron ajenos al contexto adverso.

Cabe destacar, las limitaciones de las instituciones y organizaciones populares se vieron agravadas en Bariloche por las crisis de inestabilidad política y los procesos de fragmentación social, éstos últimos desplegados en los barrios como resultado de la (falta de) planificación urbana que marginó a los sectores de más bajos recursos, dando lugar a grandes contrastes sociales dentro de la ciudad.

Si bien a fines de los años ochenta el club Arco Iris había comprado algunos de los lotes que conformaban el terreno de la cancha para salvaguardar el espacio destinado a la recreación comunitaria, lo cierto es que no pudieron comprarse todos debido a la falta de recursos para ello. Tampoco pudieron Ilevarse adelante otras obras de infraestructura básicas en el predio y, en efecto, resultó imposible formar parte de los campeonatos de LIFUBA. De esta manera, al igual que en el caso de Puerto Moreno, los equipos mayores e infantiles de Arco Iris participaban con su cancha en los campeonatos de fútbol libre barrial, entre ellos los "Interjuntas" (de las juntas vecinales) organizados por la Municipalidad.

Pues bien, sumado a la falta de consolidación institucional, durante los años noventa continuaron los conflictos respecto a la propiedad de las tierras de la cancha de Virgen Misionera. Hacia 1994, el presunto propietario original de uno de los lotes decidió construir, una vez más, una casa en el lugar, obligando a la cancha a desplazarse unos metros y reducir sus dimensiones (que recientemente habían sido ampliadas gracias a trabajos de desmonte y alisado de terreno realizados por el municipio). En los años siguientes se recrudeció el conflicto en torno al lote, alcanzando uno de sus momentos más tensos en 1997, cuando dicho poblador exhibió un poder sobre el predio e intentó alambrar un esquinero del campo de juego. En reacción, un grupo de vecinos, conformado mayoritariamente por mujeres, instaló durante algunos días una carpa en la cancha y montó una vigilia exigiendo la mediación de las autoridades municipales para resolver el conflicto. Cabe destacar, la instalación de carpas se popularizó como forma de protesta social y sindical en Argentina durante los años noventa, ya que permitía sostener un reclamo durante un tiempo prolongado y con una visibilización mayor que otras medidas "tradicionales" de protesta tales como las marchas ${ }^{24}$.

24. El ejemplo paradigmático fue la "Carpa Blanca" instalada por sectores docentes frente al Congreso de la Nación entre 1997 y 1999 en reclamo por mejores salarios y mayor presupuesto para el sector educativo. 
Pese al reclamo, las intervenciones de la Municipalidad (muchas veces contradictorias) contribuyeron a agravar y alargar el pleito ${ }^{25}$, lo que derivó en hechos de violencia en más de una ocasión. De esta manera, el conflicto, que tenía una compleja trama legal, social e inmobiliaria, continuó durante tres años más sin resolución judicial u otra solución consensuada.

Nuevamente, fueron la organización vecinal y las redes de solidaridad las que permitieron mantener el espacio. Para ello, el club argumentó la utilización comunitaria de los lotes por más de treinta años y la constitución de la cancha como un espacio de contención para los jóvenes del barrio frente a problemáticas sociales como la violencia, el alcoholismo, la drogadicción y "la vagancia". No sólo era un espacio aprovechado por el club (allí se realizaban campeonatos interbarriales, infantiles y de fútbol femenino), sino también utilizado por los estudiantes que concurrían a las escuelas y asociaciones del lugar (incluyendo la escuela primaria Virgen Misionera, el secundario Amuyén y el taller Carlos Mugica).

Sumado a la defensa del espacio, el terreno de la cancha pudo ser ampliado con apoyo de la Fundación Gente Nueva y de las demás instituciones educativas del barrio. Esto incluyó el inédito cierre de una calle que cruzaba la cancha, que fue convertida en peatonal permitiendo ganar los metros necesarios para que el campo tuviera las medidas reglamentarias oficiales. De esta manera, con gran ayuda de los vecinos, el club terminó de acondicionar su cancha de tierra y colocar el alambrado olímpico para participar en los campeonatos de LIFUBA a partir del año 2002. Además, los dirigentes y colaboradores de Arco Iris organizaron partidos amistosos contra equipos de la zona oeste con el objetivo de recaudar fondos para emprender la participación en el fútbol federado. Sumado a esto, se incorporaron más vecinos para trabajar en el club y humildes comercios del barrio aportaron contribuciones económicas.

Pues bien, resulta significativo que estos logros e iniciativas se hayan dado en el peor momento económico de la Argentina y cuando la situación social golpeaba de forma más dura a la población de Virgen Misionera. Poco tiempo después, el equipo de primera de Arco Iris salió campeón del torneo local en la temporada 2003-2004, lo que conmocionó a la gente del barrio por ser un hecho totalmente inesperado debido a la austeridad de los recursos y al detalle de que se trataba de un plantel de jugadores oriundos de la zona. Este éxito le permitió a la institución participar en el Torneo del Interior (el Argentino " $\mathrm{C}^{\prime \prime}$ ) organizado por el Consejo Federal del Fútbol Argentino. De esta manera, en

25. Existieron proyectos de ordenanza que proponían declarar los lotes de la cancha como de utilidad pública, a la vez que se permitiría al vecino implicado ampliar su predio hacia otro sector. Sin embargo, estas iniciativas no tuvieron éxito. Simultáneamente, en otras ocasiones el municipio contribuyó al cercamiento del terreno y desconoció resoluciones judiciales que otorgaban la tenencia del lote al club Arco Iris. 
muy poco tiempo se convirtió en el club más popular de Bariloche, con una hinchada que acompañaba al equipo en gran número en cada una de sus presentaciones ${ }^{26}$, incluso en los torneos realizados fuera de la ciudad, en los cuales Arco Iris tuvo varias actuaciones destacadas. La afición no estaba compuesta sólo por vecinos del barrio, sino también provenientes de otros lugares de la ciudad. Por otra parte, cada vez más comercios y empresas de todo Bariloche comenzaron a brindar su patrocinio.

El "Fenómeno Arco Iris" motivó una popularización de todo el fútbol local. El barrio dejó de ser noticia por hechos delictivos y los vecinos comenzaron a sentirse orgullosos de los logros deportivos. De igual forma, pobladores del Alto y del oeste vieron en el fútbol un espacio para ganarse un lugar en la sociedad y, de esta manera, disipar los estigmas que muchas veces pesan sobre ellos por la residencia en ciertos barrios o sectores de Bariloche. Como resultado, las canchas de toda la ciudad empezaron a tener asistencia masiva los días de partido, lo que no es un hecho menor, considerando que los encuentros de la Liga de fútbol local históricamente suelen tener poca concurrencia de espectadores. En este momento se creó la rivalidad futbolística entre el equipo de Virgen Misionera y el San Cayetano Derby Club, el equipo del barrio Frutillar (también de composición popular, ubicado en el sudoeste del casco urbano), que contaba con la segunda hinchada más numerosa de Bariloche. Otro proceso destacado generado por el "Fenómeno Arco Iris" fue una dinamización del mercado de pases y préstamos de jugadores, algo también inédito a nivel local.

Por otra parte, el caso de Puerto Moreno presenta claras similitudes con el que acabamos de repasar. Las complicaciones del club durante los años noventa pusieron en riesgo en más de una oportunidad el mantenimiento del usufructo del terreno cedido a préstamo por la CNEA. Por eso, el retorno al fútbol federado fue una necesidad ya que implicaba volver a adquirir una personalidad jurídica y reasumir sus obligaciones como sociedad civil, que eran la razón de ser del permiso para la utilización del predio. Ante la exigencia de LIFUBA de contar con personería jurídica, en 1999 se inició un acuerdo con la Asociación Vecinal Pájaro Azul. Así, Puerto Moreno disputó las competencias de la Liga hasta el año 2003 bajo el nombre "Pájaro Azul-Puerto Moreno". En esta etapa, el club tuvo importantes éxitos deportivos (principalmente la consecución del campeonato 2002-2003 de LIFUBA) y pudo afrontar los gastos de los torneos gracias al aporte de la Asociación Vecinal. Además, el sostenimiento institucional fue posible gracias a pocas personas que desempeñaban múltiples

26. Un promedio de 500 personas acompañaba al equipo en los partidos regulares, y más de 1000 lo hacía en las instancias decisivas. Por aquel entonces, Arco Iris incluso rompió récords de asistencias en el Estadio Municipal de Bariloche. Se trata de números que superan ampliamente las cifras que hasta el día de hoy registran los encuentros del fútbol local. 
funciones. De hecho, tanto en Puerto Moreno como en Arco Iris fue recurrente la figura del "jugador-dirigente" 27 .

El vínculo Pájaro Azul-Puerto Moreno se basó en la obtención de un beneficio mutuo para las dos partes involucradas. En esta alianza, que vamos a denominar como una relación de "mutualismo" o "simbiosis institucional" ${ }^{28}$, el club recibía de la Asociación los recursos necesarios para el desarrollo futbolístico, a la vez que ésta última podía incentivar las actividades sociales y culturales del barrio a través de la entidad deportiva. Es decir, la junta vecinal se puso al servicio del club deportivo, entendido como un ámbito de participación ciudadana más informal en el espacio público. En un contexto de crisis que amenazaba el buen desarrollo institucional, la alianza fue necesaria y da cuenta de otra estrategia del club para mantenerse con vida.

El estallido de la crisis de 2001 en Argentina deriva de las políticas neoliberales aplicadas durante los años noventa que causaron un crecimiento de la pobreza $^{29}$ y la polarización social en todo el país. Esas políticas impactaron sobre el turismo en Bariloche, es decir, la principal actividad económica, aumentando notablemente los niveles de pobreza y exclusión social. Además, se manifestaron, una vez más, a través de un modelo de ciudad favorable a los intereses del sector inmobiliario, que propició mayor fragmentación socio-espacial en Bariloche y dificultó aún más el acceso a la propiedad de la tierra como ocurrió en Virgen Misionera.

En este momento, Puerto Moreno también trascendió la zona oeste y permitió que jóvenes varones de los barrios marginados del Alto puedan ser integrados a través del deporte. Esto se vio favorecido por los lazos de solidaridad que el club entabló durante sus años en el fútbol libre, conexión que no es tan común en el fútbol federado. A su vez, la institución reforzó los vínculos con los vecinos de su barrio. La alianza con la Asociación Vecinal Pájaro Azul, la obtención del campeonato de la primera categoría local y la cobertura periodística

27. Al momento de ingresar a la Liga de Fútbol Bariloche, Marcelo Gualmes y Gabriel Guerrero eran presidentes de sus clubes y a la vez figuras de sus equipos, Arco Iris y Puerto Moreno respectivamente.

28. Desde la biología, el mutualismo es, a grandes rasgos, una relación, generalmente no obligatoria, que se establece entre dos individuos de diferentes especies, en donde ambas partes salen beneficiadas por la interacción y logran mejorar su eficacia adaptativa frente a amenazas que pueden poner en riesgo su supervivencia. La simbiosis es un tipo particular de mutualismo más íntimo en el que al menos una de las partes es estrictamente dependiente de la otra para poder sobrevivir. Llevado el concepto al análisis social, en este caso, el club Puerto Moreno necesitó la personería jurídica de la Asociación Vecinal para poder competir en el fútbol federado, conservar su cancha y, en definitiva, poder sobrevivir como institución.

29. Para ampliar información al respecto véase Nataine, D. y Simonelli, A., "La prescindibilidad de los puestos laborales en servicios turísticos básicos de San Carlos de Bariloche", Realidad. Tendencias y desafíos en turismo. Neuquén 2001, pp. 104-112. 
de las campañas del equipo ${ }^{30}$ favorecieron la integración del club al interior de la identidad barrial.

Sin embargo, a fines de 2001 se produjeron serios incidentes en un partido de Puerto Moreno contra el combinado de Alas Argentinas ${ }^{31}$. Como resultado de las sanciones económicas aplicadas por LIFUBA a raíz de este suceso $-y$ otros que tuvieron como protagonistas a jugadores, hinchas y dirigentes de la institución-, la Asociación Vecinal Pájaro Azul decidió dar por concluida su simbiosis con el club. Este último, por su parte, tuvo que comenzar a gestionar su propia personería jurídica. Por lo tanto, la violencia en el fútbol fue un gran obstáculo para las actividades de Puerto Moreno. Estos hechos, que también eran muy recurrentes en las populosas presentaciones de Arco Iris (llevando incluso a divisiones al interior de su hinchada), reflejaron la conflictividad social de la población local en momentos de crisis y muestran cómo las actividades deportivas son permeables a su contexto específico. En este punto, como plantea Gabriel Cachorro, las prácticas deportivas están movidas por subjetividades particulares, ya que a través de ellas se manifiestan deseos, frustraciones, angustias y satisfacción ${ }^{32}$.

\section{Los trabajos con las categorías infantiles en la etapa post-neoliberal}

A partir del 2003, la Argentina tuvo una recuperación económica motivada por los precios favorables en el mercado internacional de las materias primas exportadas. De acuerdo con Martín Astarita, Javier Cachés y Mariano Montes, la reactivación post-neoliberal permitió a los gobiernos kirchneristas (2003-2015) implementar políticas que conllevaran una mayor redistribución de la riqueza con la consiguiente dinamización del mercado interno ${ }^{33}$. Las mejoras económicas ayudaron a reducir los niveles de desempleo, pobreza y desigualdad social. Sin embargo, en Bariloche continuaron desarrollándose los procesos de segregación socio-espacial junto a la presencia de jóvenes en situación de calle. En

30. Puerto Moreno y Arco Iris contaban con el apoyo de humildes emisoras de radio que realizaban un seguimiento de sus respectivos equipos.

31. Los hechos se produjeron el 20 de diciembre de 2001. Es decir, el mismo día que Fernando De la Rúa (Alianza UCR-FREPASO) renunció a su cargo como presidente de la Nación luego del estallido social producido los días previos. Aquella semana estuvo marcada por saqueos, robos, piquetes y movilizaciones populares generalizadas en la Argentina agrupadas bajo la consigna de "¡Que se vayan todos!", las cuales fueron contrarrestadas con una feroz represión policial que dejó cerca de treinta muertos en todo el país. Estos graves hechos de violencia también tuvieron su réplica en San Carlos de Bariloche.

32. Cachorro, G., "Deporte, prácticas corporales y subjetividad", Revista Artefacto (27). Buenos Aires 2009, p. 3.

33. Astarita, M., Cachés, J. y Montes, M., "Planificación Estratégica Gubernamental en un entorno Democrático, Lecciones de América Latina: el Caso de Argentina", Planeamiento Estratégico Governamental em Contexto Democráctico: Liçoes da Amérca Latina, Brasilia 2014. 
este contexto, los dos clubes del oeste llevaron adelante la conformación de sus categorías de fútbol infantil.

En 2004, la Comisión Directiva de Puerto Moreno buscó reorganizar el club luego de la experiencia junto a la Asociación Vecinal Pájaro Azul. Se apuntó a mejorar la infraestructura y formar dirigentes para evitar las pugnas internas y la ineficiente administración de los recursos. Además, como acabamos de decir, se crearon las divisiones infantiles, orientadas a contener a los niños y satisfacer sus necesidades recreativas frente a la dura realidad social. Ese comienzo se dio con pocos elementos materiales. Pero las nuevas categorías quedaron a cargo de entrenadores capacitados por la Asociación de Técnicos del Fútbol Argentino. Esto resulta significativo ya que no abundan los técnicos profesionales en Bariloche.

En el otro caso, en el marco del "Fenómeno Arco Iris" generado a partir de los logros deportivos, el club de Virgen Misionera asumió la responsabilidad de proporcionar un espacio de formación e integración para niños y jóvenes a través de la práctica del fútbol. Si bien ya se venía trabajando desde los años anteriores, en 2003 se conformaron las primeras categorías formales para participar en los torneos del Departamento Infanto-Juvenil de LIFUBA. Ese comienzo fue posible con la colaboración activa de un grupo de madres y otros vecinos que llevaron adelante las clásicas ventas de empanadas y rifas para obtener los recursos necesarios. A partir de allí, al igual que en Puerto Moreno, fue cada vez mayor el acercamiento de niños y adolescentes al club y se consolidó aún más el anclaje identitario barrial de los vecinos en torno a la institución. Aunque cabe aclarar que la cantidad de categorías tuvo varias fluctuaciones en los años siguientes debido a los lógicos costos que implicaba mantenerlas.

En ambos casos, el empuje de los dirigentes y los vecinos permitió a los planteles del fútbol infantil formar parte de competencias en otras ciudades de la región e incluso en Chile, lo cual resultó un gran incentivo para la integración de los niños.

\section{La refundación del club Puerto Moreno y el crecimiento de Arco Iris}

En los años posteriores, Arco Iris y Puerto Moreno tuvieron importantes procesos de crecimiento, si bien las dificultades económicas siempre han sido una constante. Con apoyo de la comunidad del barrio, Arco Iris pudo llevar adelante en 2003 la construcción del paredón perimetral de la cancha y, más adelante, en 2006, concretó la edificación de los vestuarios gracias al trabajo de arquitectos ad honorem. Para que ello fuera posible, el Equipo Pastoral de Tierras se encargó de la regularización dominial de los lotes donde también se llevarían adelante otros proyectos futuros, incluyendo el armado de una sede.

El empuje dado a partir del campeonato de primera división le permitió al club de Virgen Misionera incorporar jugadores y dirigentes de mayor jerarquía deportiva. De la mano de ello, en los años siguientes se conformaron equipos 
de fútbol de salón y se creó una subcomisión de fútbol femenino para participar en las competiciones del Departamento Femenino de LIFUBA. Además, durante un corto período de tiempo se dio impulso a una escuelita de básquet y se armó un equipo que tuvo un exitoso paso por los torneos de la Asociación de Básquet de Bariloche. Entre otras cuestiones, Arco Iris incluso llegó a contar por estos años con su propia línea de merchandising.

Puerto Moreno, por su parte, ante la imposibilidad de reflotar su personería jurídica, dejó de llamarse "Club Atlético Puerto Moreno" en el año 2008 para convertirse en la "Asociación Civil, Cultural y Deportiva Puerto Moreno". En ese momento de "refundación" se veló por el cumplimiento de las obligaciones civiles de la institución y se reasumió el compromiso de posibilitar que los niños y jóvenes puedan contar con un espacio para realizar un deporte que los aleje de las calles. Para concretar sus objetivos, la dirigencia buscó ampliar los ingresos del club. La falta de dinero para las competencias fue paliada con el aporte de algunos comercios interesados en apoyar la labor contenedora desarrollada con los jóvenes. Además, la institución continuó recibiendo aportes de la Asociación Vecinal Pájaro Azul y buscó atraer contribuciones de "socios protectores".

Por otra parte, los trabajos de la dirigencia estuvieron acompañados por un pequeño grupo de padres de jugadores que comenzaron a colaborar activamente con el buen funcionamiento del desarrollo deportivo e institucional. Con éste y otros aportes pudo impulsarse la construcción del quincho de la sede social del club, junto con la incorporación de una instalación eléctrica trifásica y una bomba para el sistema de riego de la cancha. Además, el diálogo con las autoridades del Centro Atómico Bariloche (CNEA) permitió concretar un nuevo convenio de utilización del predio.

En ambos casos, la cuota societaria constituyó la base económica de los clubes, aunque cabe aclarar que se trataba de montos mensuales bajos para hacer posible la integración de niños y jóvenes en condiciones de pobreza. A esto se sumaron los ingresos generados por el alquiler de las instalaciones y la realización de eventos sociales, lo que permitió continuar con las mejoras en los espacios. Por otra parte, las instituciones de "los Kilómetros" profundizaron los trabajos con el fútbol infanto-juvenil e impulsaron la profesionalización de sus cuerpos técnicos bajo la proyección de que, al tener gente capacitada encargada de la formación de los niños, se vería menos violencia en las canchas. La idea era evitar que el fútbol infantil refleje los incidentes que se registraban recurrentemente en el fútbol mayor, los cuales eran un correlato de la conflictividad latente en la ciudad, que estalló en coyunturas críticas.

La represión policial en Bariloche que acabó con el asesinato de tres jóvenes en junio de $2010^{34}$ y los saqueos en varios comercios en diciembre de 2012

34. El 17 de junio de 2010, un efectivo policial asesinó al joven Diego Bonefoi, de 15 años, en el barrio 181 Viviendas de la zona del Alto de Bariloche, en lo que es señalado como 
son hechos que dan cuenta de la exclusión social que afecta a los sectores más vulnerables. Allí se reactivaron conflictos arraigados en la población local que derivan de causas socio-económicas profundas y de tensiones generadas por los diferentes imaginarios construidos en torno a las desigualdades sociales. Los sectores populares del Alto y "los Kilómetros" comparten experiencias como las condiciones de hacinamiento, la pertenencia a minorías étnicas o colectividades latinoamericanas, las mismas condiciones laborales, las formas de marginación comunes y las maneras de percibir la realidad socio-económica.

Como asegura Maximiliano Lezcano, durante décadas estos sectores fueron excluidos de la historia oficial de Bariloche mientras el discurso hegemónico, sostenido por el Estado, la prensa y parte de la opinión pública, se encargó de estigmatizarlos y atribuir sus problemáticas a su propia responsabilidad ${ }^{35}$. De la mano de ello, las representaciones que se suelen construir desde afuera sobre los barrios populares son las que los identifican con la lejanía espacial y con la imagen de "zonas de peligro" gobernadas por la delincuencia. Se trata de un discurso que naturaliza ciertas desigualdades sociales y territoriales.

La estigmatización de los sectores populares deriva del contexto socio-económico que los define y los margina, en el marco de una fragmentación social y espacial que se vio agravada a partir del despliegue del modelo económico neoliberal en los años noventa. Frente a ello, los conflictos sociales pasaron por un cuestionamiento a la clase dirigente y a las fuerzas policiales por el abandono institucional, la represión y las grandes carencias que padecen distintas zonas de la ciudad.

La marginación originó violencia en el fútbol entre diferentes barrios. A su vez, la inacción del Estado reforzó la expansión de la misma. Además, el fanatismo dio lugar a identidades excluyentes, con un anclaje territorial, que posicionaron al rival como un enemigo. Recordemos que, dentro de su gran heterogeneidad interna, Bariloche ha atravesado un proceso de fragmentación que da lugar a identidades diversas y sectorizadas, muchas veces opuestas, que tienen como base el lugar de origen, la ubicación espacial y la situación socio-económica de sus pobladores. No obstante, el deporte también ha sido un ámbito propicio para hacer posible la integración social en contextos de marginalidad, pobreza y otras problemáticas. Para prevenir la violencia, los dirigentes de los clubes intensificaron las tareas con las categorías infantiles, fomentando valores como la solidaridad, compañerismo, respeto y disciplina deportiva, sin dejar de

un caso de "gatillo fácil". Luego de ello se desencadenó una sublevación vecinal iniciada con piedrazos contra la comisaría $\mathrm{n}^{\circ} 28$ ubicada en dicho barrio. Esto fue seguido por destrozos y saqueos en algunos comercios de la zona céntrica. Los hechos se extendieron durante tres días. En reacción, la represión policial fue implacable y terminó con la muerte de otros dos jóvenes: Nicolás Carrasco de 17 años y Sergio Cárdenas de 29.

35. Lezcano, M. J., "¿Sí o NO a Wal-Mart en Bariloche? Una perspectiva desde los sectores populares", Revista Pilquen. Viedma 2010. 
lado la recreación de los niños y jóvenes. Específicamente, en el caso de Arco Iris, se ha hecho hincapié en la idea del "trabajo como meta", consigna que tiene mucho que ver con la matriz obrera del barrio.

El abandono institucional en el ámbito del fútbol local también se ha manifestado a través de la precariedad de las canchas de la ciudad, que generalmente no cumplen con las mínimas condiciones de seguridad. Esto guarda estrecha relación con la violencia en los partidos. La falta de infraestructura constituye un problema que históricamente ha obstaculizado el desarrollo de la actividad futbolística en Bariloche. Ambos clubes del oeste han vivido en carne propia los problemas para efectuar el mantenimiento del campo de juego y garantizar la seguridad.

\section{El sembrado de la cancha de Puerto Moreno y desafíos actuales}

En los últimos años, los clubes de "Ios Kilómetros" han continuado con su desarrollo, aunque el caso de Puerto Moreno ha sido de mayor espectacularidad pese a no estar ajeno a complicaciones. En 2011 el club inició el sembrado de su cancha, que fue reinaugurada con césped a fines del 2013. A partir de allí tuvo un gran crecimiento que se tradujo en la inscripción de mayor cantidad de chicos. Este logro fue posible con el trabajo de la dirigencia, algunos vecinos, y la contribución de los patrocinadores. El nuevo campo de juego se sumó a un corto listado de canchas sembradas en Bariloche. Esto contrasta con la gran cantidad de estadios que pueden hallarse en otras ciudades del país con mejores condiciones infraestructurales. La diferencia responde al desarrollo futbolístico propio de Bariloche, marcado por la dinámica de la sociedad local, el crecimiento urbano desordenado y la poca intervención estatal en la actividad.

El municipio no ha hecho grandes aportes para los clubes del oeste y para otras instituciones de fútbol que cumplen una tarea de contención con los jóvenes, a pesar de las constantes solicitudes de subsidios u otro tipo de ayudas. Los materiales de entrenamiento que proporciona son insuficientes para todos los equipos. Además, la cesión de espacio del Estadio Municipal o de los distintos gimnasios de la ciudad por parte de las autoridades se da en horarios y épocas inadecuadas para el desarrollo de la actividad y para albergar a la gran cantidad de chicos que moviliza el fútbol infantil en Bariloche. La ausencia de espacios techados para el invierno es una dificultad que afecta a los clubes que no cuentan con gimnasios propios. Puerto Moreno y Arco Iris han recurrido a los gimnasios de las instituciones educativas más cercanas, pero la obtención de esos lugares no siempre ha sido fácil.

El gobierno nacional ha estado mucho más ausente. Las gestiones kirchneristas implementaron planes para el desarrollo deportivo en todo el país que apuntaban, entre otras cosas, al mejoramiento de canchas, la capacitación administrativa y dirigencial de las instituciones, y el acceso de toda la población 
a las actividades físicas. Ejemplos de ello fueron el programa "Nuestro Club" y el programa "Argentina es Nuestra Cancha", creados a partir del Plan Nacional de Deporte, emitido en 2008, basado en la implementación de un modelo "nacional y popular". En ellos se consideraba el deporte como un agente capaz de mejorar la calidad de vida, promover la salud, la educación y la organización comunitaria. Los clubes seleccionados adoptaron estos lineamientos, pero esa correlación discursiva no se tradujo en un apoyo estatal hacia sus actividades. El acceso a los beneficios económicos y materiales de dichos programas no fue igual en todas las regiones del país y muchas veces se vio limitado por la complejidad de los trámites burocráticos exigidos. El gobierno de Mauricio Macri tampoco ha promovido acciones sistemáticas concretas que favorezcan el acercamiento a la actividad futbolística para las personas de bajos recursos, aumentando la inversión y realizando mejoras de infraestructura ${ }^{36}$. La convergencia de políticas económicas y educativas desigualitarias resulta un obstáculo mayor para la integración de los jóvenes.

En general, los únicos aportes económicos recibidos por los clubes en cuestión han sido principalmente del gobierno de la provincia de Río Negro, destinados al avance de obras específicas. Sin embargo, se trata de ayudas esporádicas y poco continuadas, lo que deja al descubierto la ausencia de políticas coherentes destinadas a favorecer el crecimiento de las entidades deportivas barriales.

De esta manera, el reciente desarrollo institucional de Puerto Moreno se dio pese a la falta de recursos que ha impedido al club ampliar su oferta de actividades. Aun así, se realizaron mejoras en el predio, incluyendo la conexión del gas, la instalación de tribunas y una cabina de transmisión para la prensa. Por su parte, Arco Iris no ha introducido tantas mejoras edilicias (ya ha quedado muy atrás la euforia generada por el "Fenómeno Arco Iris"), pero sí ha priorizado la conformación de categorías de fútbol y hockey femenino. También pudo inaugurar una cancha sintética de "fútbol 5" para los más pequeños, a unos pasos del campo de juego principal.

Para costear sus gastos, junto con la cuota societaria, los clubes organizan cenas, ferias, y recaudan el dinero de las entradas. Los dirigentes, cuyo trabajo es ad honorem también aportan su propio capital para hacer posible la presencia de todas las categorías en los torneos oficiales y la participación en certámenes locales, regionales e internacionales (principalmente en localidades del sur de Chile). En este punto debemos considerar que los equipos que participan en las competiciones federadas deben hacerse cargo de los gastos de mantenimiento de Liga, arbitrajes, seguros, transporte para las competencias fuera de la ciudad, seguridad policial para los partidos, alquiler de

36. Este gobierno creó el programa "Clubes Argentinos", que es básicamente una continuación de los planes anteriores. Y con las mismas limitaciones para su tramitación. 
gimnasios, compra de indumentaria deportiva, sumado al pago de los viáticos de los directores técnicos.

La gran colaboración de la gente de los barrios en las actividades institucionales muestra el alto grado de integración de las familias de la zona a los clubes, siendo mucho más marcada esta característica en el caso de Arco Iris de Virgen Misionera. La creación de las categorías infantiles y la inauguración de la cancha de césped, en el caso de Puerto Moreno, favorecieron esa identificación.

Pues bien, ambas instituciones brindan espacios recreativos y realizan una tarea de contención frente a diferentes problemáticas como los conflictos familiares y el consumo de drogas. También incluyen a chicos con carencias económicas, muchos provenientes de los barrios humildes de "los Kilómetros". Virgen Misionera es uno de ellos. Allí la densidad poblacional es alta y recurrentemente reaparecen los conflictos vinculados a la propiedad de las tierras, ya que el proceso de regularización de éstas permanece inconcluso. Además, aún son elevados los niveles de desocupación, la precariedad de algunas viviendas y las insuficiencias en la calidad de las conexiones de servicios.

Frente a ello, los clubes otorgan facilidades a las familias de los jugadores que no pueden pagar la cuota, para que igual accedan al deporte. Así se busca romper los imaginarios que excluyen a los vecinos del Alto con respecto al "Centro" y que invisibilizan las realidades de "Ios Kilómetros".

Por otra parte, ambos clubes cuentan con una importante participación de mujeres que contribuyen a los desarrollos institucionales. Esto incluye dirigentes, madres de jugadores y niñas y jóvenes futbolistas, si bien hay que aclarar que Puerto Moreno no presenta categorías exclusivas de fútbol femenino como sí tiene su par de Virgen Misionera. De todas formas, en ambos clubes las experiencias de conformación de equipos femeninos han sido fugaces o discontinuadas, lo que da cuenta de los límites de los alcances de la función integradora ejercida por estas entidades. La causa de ello deriva de la confluencia entre la austeridad económica y la prioridad que se les da a otros proyectos. Ante ello, se plantea la necesidad de avanzar hacia la creación de categorías femeninas que otorguen visibilidad a las mujeres, y que los clubes contemplen sus necesidades recreativas.

\section{Conclusiones}

Si bien cada uno de los clubes seleccionados presenta sus propias particularidades institucionales y barriales, ambos casos muestran similitudes que permiten establecer comparaciones y proyectar conclusiones de mayor alcance. Por empezar, hemos visto las enormes carencias materiales que han acompañado a las dos entidades del oeste de Bariloche desde el momento de sus fundaciones. Esos comienzos se dieron por iniciativa de los vecinos de la zona en el marco del proceso de crecimiento de la ciudad, a partir de los años setenta, que dio 
lugar a la conformación de nuevas identidades barriales. El origen de los clubes corrió a la par del desarrollo de experiencias comunitarias destinadas a hacer frente a las necesidades que el Estado no podía satisfacer. En el caso de Virgen Misionera es notoria la relación que existió entre el surgimiento del club y la lucha por la tierra en un barrio que padecía la misma marginación que otros sectores de la ciudad.

La precariedad motivó el despliegue de distintas estrategias de supervivencia por parte de los clubes, no siempre con resultados exitosos. Un ejemplo de ello estuvo dado por la solicitud de subsidios a las autoridades gubernamentales. Esto motivó la "adecuación" de las instituciones a ciertos discursos emitidos desde las esferas estatales respecto al rol de la práctica del fútbol en la formación de los jóvenes. Así, en los años ochenta las organizaciones fueron difusoras de los valores democráticos a través del deporte. Sin embargo, esto no conllevó apoyos del Estado para sus actividades.

La crisis económica en los años ochenta y el despliegue de políticas neoliberales en los noventa tuvieron un impacto negativo sobre los barrios de Bariloche. Durante aquellos años, Arco Iris y Puerto Moreno se vieron seriamente limitados en su crecimiento. Por eso, entablaron alianzas con otras organizaciones para fortalecerse. En este contexto, sus equipos tuvieron pasos por el fútbol libre en una época marcada por la violencia y la desaparición de espacios públicos destinados a la actividad deportiva producto de la lógica del mercado de tierras. Ambas entidades afrontaron luchas por conservar sus canchas, que fueron defendidas por la voluntad de los vecinos. Ante ello, la mediación de las autoridades municipales fue escasa y hasta contradictoria, tal como observamos en el caso del conflicto por los lotes en Virgen Misionera.

Durante sus etapas en el fútbol libre, los clubes superaron el ámbito barrial y tuvieron un mayor acercamiento con los jóvenes de otros sectores excluidos de la ciudad, de manera que se convirtieron en espacios de inclusión al margen del Estado. Paradójicamente, Puerto Moreno y Arco Iris iniciaron sus etapas de crecimiento en el peor momento económico del país (a fines de los noventa y durante la crisis del 2001), mientras creía la pobreza en Bariloche. Los éxitos deportivos y la creación de espacios de contención favorecieron la consolidación del anclaje identitario en torno a las instituciones. El "Fenómeno Arco Iris" y la experiencia de "Pájaro Azul-Puerto Moreno" motivaron la popularización del fútbol local y la integración social de muchos vecinos.

Simultáneamente, los clubes dieron impulso a las tareas de formación por medio de sus categorías para niños y jóvenes, las cuales estuvieron orientadas a reducir la violencia en las canchas. Esa violencia reflejó la conflictividad social en coyunturas críticas donde se reavivaron tensiones de la población barilochense que derivan de causas socio-económicas y de los distintos imaginarios que coexisten. En este punto, los indicentes también han sido un obstáculo para las actividades de los clubes. Así lo demuestra el final de la alianza entre la Asociación Vecinal Pájaro Azul y el club Puerto Moreno. 
Durante los últimos años, los clubes han atravesado lentos y discontinuados procesos de crecimiento. Esto ha sido posible con el trabajo de dirigentes y vecinos, pese a la constante escasez de recursos. Dicho crecimiento incluye el desarrollo de obras de infraestructura y la intensificación de los trabajos formativos con las categorías infanto-juveniles. Todo ello ha sido posible sin aportes de las autoridades municipales y sin la intervención de los programas nacionales de fomento a las instituciones deportivas.

Entonces, a partir del abordaje por la historia de los clubes Puerto Moreno y Arco Iris intentamos dar visibilidad a las particularidades de la historia del fútbol y de la sociedad local teniendo en cuenta las dinámicas propias de la ciudad de Bariloche y el contexto nacional más amplio en que se encuentra la realidad trabajada. Se trata de un camino lleno de avances y retrocesos, en donde muchos proyectos tuvieron que ser replanteados frente a obstáculos recurrentes como los problemas económicos, las dificultades para conservar los espacios y la violencia en el fútbol. La principal continuidad que hallamos a lo largo del tiempo en la reconstrucción histórica de dichas entidades del oeste de Bariloche es la ausencia del Estado en sus distintos niveles como un actor capaz de generar políticas concretas que beneficien el crecimiento del fútbol y el fútbol infantil, y que fomente las actividades formativas y de contención social Ilevadas adelante por los clubes.

Por eso ratificamos que el desarrollo institucional de Arco Iris y Puerto Moreno, al igual que el de otros clubes de Bariloche, ha sido producto de la iniciativa de vecinos, emprendedores locales, más que de cualquier tipo de intervención sistemática del Estado. A su vez, hemos identificado que la autogestión de los clubes está muy ligada a las propias dificultades estatales para asegurar la provisión de los servicios básicos a los barrios más alejados del centro de la ciudad.

Las complicaciones señaladas pueden hacerse extensivas al conjunto de la actividad futbolística en Bariloche, considerando que las políticas económicas y de planificación urbana en las últimas décadas agravaron la exclusión social e implicaron la desaparición de numerosos espacios públicos utilizados para esa práctica deportiva. Las acciones (e inacciones) de los distintos gobiernos municipales y nacionales fueron siempre más un limitador que un impulsor de la función integradora del fútbol en Pájaro Azul, en Virgen Misionera y en toda la ciudad, ya que no realizaron aportes significativos al crecimiento y desarrollo de la práctica deportiva.

Por otra parte, vimos a partir del discurso sostenido por las dirigencias de los clubes que las actividades deportivas pueden ser medios formadores de los ideales de una época incluso sin que haya intervención estatal. Frente a la marginalidad y el abandono del Estado, los barrios y los clubes de fútbol se muestran como ámbitos de sociabilidad, de experiencias asociativas, de creación de estrategias inclusivas y de constitución de diversas identidades colectivas. En definitiva, se constituyen como espacios de resistencia frente a la exclusión social y la ausencia de políticas que ayuden a reducir las desigualdades. 


\section{Bibliografía}

Astarita, M., Cachés, J. y Montes, M., "Planificación Estratégica Gubernamental en un entorno Democrático, Lecciones de América Latina: el Caso de Argentina", Planeamiento Estratégico Governamental em Contexto Democráctico: Liçoes da Amérca Latina. Brasilia, 2014.

Bandieri, S., "Acerca del concepto de región y la historia regional: la especificidad de la Norpatagonia", Revista de Historia, 5, 1995, pp. 277-293.

Barelli, A. I. y Azcoitía, A., "Construcciones identitarias hegemónicas y estrategias sociorreligiosas de visibilización de los migrantes latinoamericanos en San Carlos de Bariloche (1970-2000)", Quinto Sol, 19 (2), 2015, pp. 1-21. http://doi.org/10.19137/qs.v19i2.1046.

Boucher, D. G., James, S. y Keeler, K., "The ecology of mutualism", Annual Review of Ecology and Systemattics, 13, 1982, pp. 315-347. https://doi. org/10.1146/annurev.es.13.110182.001531.

Cachorro, G., "Deporte, prácticas corporales y subjetividad", Artefacto: pensamientos sobre la técnica, 27, 2009.

Caravaca, E., "Protesta social reciente: Entre el silencio y el estallido", Memoria Académica. La Plata, 2010, pp. 2-15.

Chiappe, M., "¡A la pelota! Fútbol, popularidad y hombría. Entre la sociedad civil y la intervención estatal. Bariloche, 1920-1945", Méndez, L. y Podlubne, A. (comps.), Tiempo de jugar, tiempo de aprender. Educación, museos y prácticas corporales en la Patagonia Norte, 1910-1955, Buenos Aires, 2016.

Di Domizio, D., "Análisis de las Representaciones Sociales sobre la Vejez en Políticas Públicas que incluyen prácticas corporales para adultos mayores: los casos del Plan Nacional de Deporte y los Juegos Deportivos", Kairós Gerontología 15 (1), 2012, pp. 21-33.

Gerlero, J. C., "La imposición del ocio. Características del Modo de Recreación de la última dictadura militar en Argentina", Educación física y deporte, 31 (2), 2012, pp. 997-1007.

Guevara, T. A., "¿Y el título para cuándo? El proceso de regularización del barrio Virgen Misionera", Cadernos Metrópole 18 (35), 2016, pp. 119-144.

Iñigo Carrera, N. y Cotarelo, M. C., "Génesis y desarrollo de la insurrección espontánea de diciembre de 2001 en Argentina", Sujetos sociales y nuevas formas de protesta en la historia reciente de América Latina. Buenos Aires, 2006, pp. 50-90.

Jalil, J., El deporte de mi pueblo. Bariloche, 2003.

Kropff, L., "Migración e identidad en San Carlos de Bariloche", V Congreso de Antropología Social. La Plata, 1997.

Levi, G., "Sobre microhistoria", Burke, P., Formas de hacer historia, Madrid, 1991, pp. 119-143. 
Lezcano, M. J., “¿Sí o NO a Wal-Mart en Bariloche?: una perspectiva desde los sectores populares del 'alto'", Pilquen: sección Ciencias Sociales, 13, 2010.

Martins, F., "Masculinidades y enseñanza del fútbol en el ámbito de los clubes. Niños y jóvenes entre 10 y 14 años de la ciudad de San Carlos de Bariloche 2016-2017", Tesis de Maestría en Ciencias Sociales y Humanidades, 2017.

Matossian, B., "Dimensiones objetivas y subjetivas de la segregación urbana: el caso de San Carlos de Bariloche", XI Jornadas Argentinas de Estudios de Población. Asociación de Estudios de Población de la Argentina. Neuquén, 2011.

Méndez, L., Estado, frontera y turismo. Historia de San Carlos de Bariloche. Buenos Aires, 2010.

Mendoza, L., El Baby Fútbol ¿Productor o reproductor de masculinidades? El fútbol infantil en San Carlos de Bariloche en la primera mitad del siglo XX. Bariloche, s/f.

Moreira, C. y Barbosa, S., "El kirchnerismo en Argentina: origen, apogeo y crisis, su construcción de poder y forma de gobernar", Sociedade e Cultura 13 (2), 2010, pp. 193-200.

Nataine, D. y Simonelli, A., "La prescindibilidad de los puestos laborales en servicios turísticos básicos de San Carlos de Bariloche", Realidad. Tendencias y desafíos en turismo, 2001.

Nestares, J. A., Clase de fútbol. Sectores populares y asociativismo deportivo en Bariloche. La experiencia de la ADEFUL (1975-2015), Bariloche, 2015.

Núñez, P. y Fuentes, R. D., "Formas de participación en procesos democráticos recientes. Sociedad civil en San Carlos de Bariloche", Recerca: Revista de pensament i Analisi, 8, 2008, pp. 193-213.

Núñez, P. y Guevara, T., "La ciudad en disputa: desarrollo urbano y desarroIlo económico en San Carlos de Bariloche, Argentina", Diálogo Andino, 45, 2013 pp. 153-167.

Rein, R., La cancha peronista. Fútbol y política (1946-1955). Buenos Aires, 2015.

Rodríguez, L. G., "Cambiemos: La política educativa del macrismo”, Questión. Revista Especializada en Periodismo y Comunicación 1 (53), 2017, pp. 90106.

Wanschelbaum, C., "La educación durante el gobierno de Raúl Alfonsín (Argentina, 1983-1989)", Ciencia, docencia y tecnología, 48, 2014, pp. 75-112. 